\title{
LA INVESTIGACIÓN ANTROPOLÓGICA Y OSTEOLÓGICA EN CEMENTERIOS
} AFRODESCENDIENTES

ANTHROPOLOGICAL AND OSTEOLOGICAL RESEARCH IN AFRO-DESCENDANT CEMETERIES 


\title{
La investigación antropológica y osteológica en cementerios afrodescendientes
}

\author{
Antonio David Pérez
}

Resumen: En este artículo se aborda el área osteología de rescate, definida por Urosa como recuperación, cuidado y conservación de piezas óseas desatendidas y olvidadas, las cuales pueden otorgar una cantidad incomparable de datos para el entendimiento de los asentamientos y sus dinámicas en el pasado. El objetivo de este artículo es mostrar la utilidad de la osteología para avanzar específicamente en los estudios sobre afrodescendientes. Para ello, se realizó una recopilación de autores cuyas investigaciones demuestran la productividad cognoscitiva de la osteología en la investigación de cementerios con enterramientos de antiguos esclavizados y sus descendientes. Finalmente, se expone un estudio de caso reciente en un antiguo cementerio de esclavizados en Venezuela.

\section{Palabras Clave:}

Antropología, Osteología, Cementerios Afrodescendientes.

\begin{abstract}
This article deals with the rescue osteology area, defined by Urosa as recovery, care and conservation of neglected and forgotten bone pieces, which can provide an incomparable amount of data for the understanding of settlements and their dynamics in the past. The objective of this article is to show the usefulness of osteology specifically in advancing studies on people of African descent. For that a compilation of authors whose research demonstrates the cognitive productivity of osteology in the investigation of cemeteries with burials of former slaves and their descendants was made.
\end{abstract}

\section{Keywords:}

Anthropology, Osteology, African descendants Cemetery.

\footnotetext{
${ }^{a}$ Antropólogo - Universidad Central de Venezuela, Venezuela. E-mail: antonio.d.perez.m@gmail.com
} 


\section{OSTEOLOGÍA}

Antes de iniciar el recorrido en materia de la relación entre osteología, rescate y estudios en cementerios afrodescendientes, es relevante dar una somera explicación sobre los contextos investigativos de la osteología, el rescate arqueológico y los tipos de abordaje que han sido llevados a cabo en cementerios.

Primeramente debemos definir la osteología como..."una de las áreas de la antropología física que utilizada interdisciplinariamente nos proporciona numerosos elementos para la reconstrucción y conocimiento de los procesos evolutivos y la identificación de las características biológicas de un individuo o de un grupo poblacional"... (Urosa, 1998, p. 9). Desde este punto de vista, la osteología es sin lugar a dudas una de las herramientas más efectivas para efectuar reconstrucciones históricas de poblaciones pasadas. Siguiendo lo mencionado por Urosa, también se puede definir a la osteología como..."una herramienta teórico-metodológica indispensable, puesto que la misma aborda el estudio de los huesos humanos desde un enfoque poblacional y cultural"... (Morales, 2004, p. 10).

A través de estas reconstrucciones, se realiza algo entendido como osteobiografía, descrita como una herramienta que... "se utiliza como medio para comprender el estudio de los restos humanos dentro de un contexto arqueológico" (Zakrzewski, 2017, p. 134) y a su vez permite dar respuesta..."a cuestiones tales como el origen biológico de los restos, su identificación como individuales o múltiples, (...), es decir, identificar el sexo, la edad, grupo étnico, estatura"... (Barrales, 2008, p. 3).

En otras palabras, la osteología permite al investigador entender el contexto físico y cultural de los individuos a quienes pertenecieron dichos restos óseos, y el entendimiento de esto es fundamental para la descripción y el análisis de los procesos socio-históricos que involucraron a las poblaciones del pasado.

Asimismo, debemos tener en cuenta a la arqueología como una disciplina antropológica que se encarga del rescate histórico y social de elementos que se encuentran en riesgo de desaparición, que al mismo tiempo da paso a la bioarqueología, definida como la..."especialización temática en la antropología física o arqueología que estudia restos humanos desde un enfoque biocultural, en su contexto y como parte integrante del cuerpo de información arqueológica"... (Tiesler Blos, 2006, p. 33), complementando de esta manera la definición de osteología y la aplicación del rescate, que más allá de ser físico se presenta de manera social y cultural e inclusive identitario.

Al mismo tiempo, la bioarqueología ha servido como lente analítica para cambiar la forma de entender los restos óseos excavados, pasando de una perspectiva individual hacia una poblacional, incorporando la injerencia del medio ambiente dentro del desarrollo y adaptación de los grupos humanos a su entorno, y la aplicación de metodologías que permiten comprender la constante interacción entre biología y cultura (Gómez Mejía, 2012, p. 193). A su vez, y según otros 
autores, en la bioarqueología "los restos óseos humanos constituyen [...] los restos materiales de seres que en la vida y luego también en la muerte, estuvieron impregnados en un mundo de cultura" (Mendonça, Bodarch y Arrieta, 2012, p. 24).

Dentro de esta área investigativa destacan los mencionados Tiesler Blos, Gómez Mejía, Mendonça, Bodarch y Arrieta, realizando aportes primordiales aunque desde perspectivas diferentes. Por ejemplo la autora Tiesler Blos (2006), elaboró una especie de manual para orientar a los futuros investigadores sobre cómo abordar los restos óseos en contextos arqueológicos. Seguidamente, las investigaciones de Juliana Gómez Mejía tienen como propósito el abordaje de...“los procesos de estrés y adaptación en poblaciones antiguas" (Gómez Mejía, 2012, p. 192), donde el análisis en conjunto del medio ambiente y las piezas óseas arrojaron información relevante sobre la interacción de estos dos elementos. Finalmente, Mendonça, Bodarch y Arrieta (2012) presentan una compilación de los resultados de investigaciones en el ámbito bioarqueológico sobre el rescate de identidad de individuos enterrados colectivamente y el análisis del contexto funerario que se encontrase asociado al sitio, así como también llevaron a cabo abordajes orientados hacia la reconstrucción de estilos de vida, todas realizadas en conjunto por sus equipos de trabajo a lo largo de 20 años de experiencia y alrededor de casi toda la Argentina.

En el mismo orden de ideas, se encuentra que comúnmente la osteología es utilizada por la antropología física-forense ${ }^{1}$, la cual primordialmente tiene como objetivo la devolución de la identidad a los restos óseos recuperados que formen parte de algún proceso legal. Dentro de esta línea de experticia, en Venezuela se encuentra el abordaje efectuado por Carvajal, quien realiza un análisis osteológico con el fin de asignar la afinidad racial a través de una muestra que él mismo reseña como...."un grupo de 50 maxilares inferiores masculinos venezolanos contemporáneos (...) obtenidos de la División de Antropología Forense, de la Coordinación Nacional de Ciencias Forenses del CICPC"... (Carvajal, 2011, p. 10). Dentro del mismo país, se advierte el estudio realizado por Chaguan, con una muestra osteológica examinada para observar 4 variables: sexo, edad, afinidad racial y estatura, extraída de...."un caso del Área de Antropología Forense, adscrita al Departamento de Ciencias Forenses, Delegación Estadal Aragua del Cuerpo de Investigaciones Científicas Penales y Criminalísticas CICPC"... (Chaguan, 2012, p. 53).

Del mismo modo, en Argentina, se encuentra el Equipo Argentino de Antropología Forense (EAAF, 2005), el cual realizó una importante labor en pro de identificar restos de los mártires de la dictadura, tras la..."recopilación y análisis de toda la información referente a las inhumaciones clandestinas en el cementerio de San Vicente"... (EAAF, 2005, p. 13) bajo la finalidad de... "cruzar los diferentes datos (número de víctimas, fechas de desaparición, fechas de enterramientos, certificados de defunción emitidos, etc.) para llegar a establecer hipótesis sobre la identidad de las víctimas"... (EAAF, 2005, p. 13). Este trabajo se efectuó con los restos de las personas asesinadas durante la dictadura que padeció Argentina entre los años de 1976 y 1983, y fue sólo a través de las reconstrucciones osteobiográficas junto con... "muestras de sangre y mucosa bucal de los presuntos

\footnotetext{
${ }^{1}$ En contextos legales, los restos óseos a analizar no provienen necesariamente de camposantos.

PÉREZ, Antonio David. La investigación antropológica y osteológica en cementerios afrodescendientes. Cadernos do Lepaarq, v. XVI, n.33, p. $126-$ 149, Jan-Jun. 2020
} 
familiares"... (EAAF, 2005, p. 31) que se logró aportar datos sobra la identidad de las víctimas. Con los trabajos de Carvajal (2011), Chaguan (2012) y la EAAF (2005) se confirma el planteamiento expuesto anteriormente sobre el estado de los abordajes en materia osteológica, siendo reducidos casi exclusivamente al ámbito legal.

Seguidamente, se encuentra en Venezuela la primera incursión dentro de la osteología de rescate a cargo de María Urosa, saliendo del ámbito forense y enfocándose en la bioarqueología, desarrollada en el Parque Histórico - Arqueológico "San Felipe El Fuerte" en el estado Yaracuy, donde los restos óseos a estudiar pertenecieron a la época colonial y de los cuales no fue asignada su afinidad racial. Las piezas óseas rescatadas fueron extraídas de una fosa común creada especialmente dentro del territorio del parque para la acumulación del material sin discriminar su tipología, bien fuere osteológico o arqueológico². Este abordaje fue considerado por Urosa como... "un estudio de una colección ósea abandonada, descontextualizada y en malas condiciones de conservación e integridad." (Urosa, 1998, p. 10).

El abordaje se centró en la recuperación y extracción de los restos óseos depositados en la fosa. Urosa recuperó piezas fragmentadas y en muy mal estado de conservación de cráneos, maxilares inferiores, clavículas, arcos costales, vértebras, conjuntos pelvianos y huesos largos (húmero, ulna, radio, fémur, tibia y fíbula). Sin embargo, la muestra extraída fue de los siguientes huesos largos: húmeros (36 piezas), fémures (112 piezas) y tibias (67 piezas), pues estos fueron los que se encontraban en mejor estado y se hallaron en mayor cantidad. No obstante, no fue analizado todo el material discriminado, pues se seleccionó únicamente los restos óseos derechos de cada uno de esos tres grupos de huesos. El conteo quedó finalmente con... "20 húmeros, 66 fémures y 36 tibias"... (Urosa, 1998, p. 41) efectuando entonces un abordaje absolutamente interdisciplinario partiendo desde la bioarqueología.

Consecutivamente, se pueden advertir distintos tipos de abordajes antropológicos en cementerios que no involucran necesariamente el análisis de los restos óseos, sin embargo no se les resta relevancia, pues los estudios de la muerte forman parte fundamental de la antropología, pues paradójicamente la muerte es una de las mejores fuentes para el entendimiento de la vida, lo que colabora al rescate histórico y cultural. Uno de los primeros investigadores en resaltar la importancia del estudio de la muerte fue Binford (1971), quien menciona que los cementerios son usualmente los sitios más encontrados por los arqueólogos y que son estos lugares los que permiten de cierta manera, entender los procesos y ritos religiosos de las poblaciones del pasado.

\section{Cementerios}

Siguiendo lo mencionado con antelación, se presentan los estudios en materia de

\footnotetext{
2 Es relevante mencionar que el abordaje de Urosa consistió en un re-estudio de piezas obtenidas en excavaciones anteriores, sin embargo estos restos habían sido abandonados en la fosa común.
}

PÉREZ, Antonio David. La investigación antropológica y osteológica en cementerios afrodescendientes. Cadernos do Lepaarq, v. XVI, n.33, p. 126149, Jan-Jun. 2020 
cementerios donde los restos óseos no fueron el objetivo principal, sin embargo, se trata de estudios fundamentales para el entendimiento de la muerte y sus contextos históricos y sociales. De esta manera la primera investigación a presentar es la efectuada por Nancy Flood (1991) de Canadá, quien elaboró un estudio demográfico sobre los cambios en los estilos de vida de los ciudadanos canadienses manejando los cementerios como fuentes de datos. Las necrópolis se utilizaron para la medición de la supervivencia de las personas dentro del país, siendo una propuesta innovadora y poco tradicional ya que los estudios demográficos tradicionalmente se realizan de casa en casa y la información se obtiene a través de encuestas socio-económicas. En este caso la labor se efectuó con actas de defunción, contextualizando las fechas de muerte para producir una explicación sociohistórica de las defunciones de los individuos.

Posteriormente en Venezuela, otro tipo de trabajo privilegia la estructura y ubicación de los cementerios, así como su repercusión en la formación social y cultural de una nación, lo cual se aprecia en la obra de Alberta Zucchi, quien investigó sobre la... "diversidad y complejidad de las formas, conceptos y creencias relacionadas con la muerte que caracterizan a los grupos autóctonos venezolanos"... (Zucchi, 2000, p. 126). A la vez, en esta misma incursión, Zucchi realizó una reconstrucción de la dinámica entre el hombre y "el sueño eterno" desde el lente de la antropología de la muerte, advirtiendo que:... "la muerte no constituye la negación de la vida sino un pasaje ontológico y existencial, es decir, un cambio de estado y una reorganización de la persona anterior"... (Zucchi, 2000, p. 115). Esto a su vez va más allá del entendimiento del cementerio sólo como un espacio físico donde reposan los cuerpos de los que partieron hacia el otro mundo, pues la mencionada autora muestra a las necrópolis como dominios llenos de elementos semióticos para el estudio de la muerte sin ser requerida una intervención arqueológica ni osteológica.

Seguidamente desde Colombia, Paula Velásquez plantea la concepción de los cementerios como lugares intersticiales, esbozando que..."determinados momentos históricos configuraron formas de asumir la muerte, representarla y ubicarla (...) como un proyecto de interés religioso, político, jurídico y económico"... (Velásquez, 2009, p. 27). Del mismo modo presenta los camposantos bajo un concepto de no lugares enmarcado en las definiciones de Augé (1992, p. 40). Dentro de su disertación también muestra un interés histórico y político para abordar el estudio de las necrópolis a lo largo del tiempo. En la misma área temática desde México advierten Aguilera y González sobre el uso de los cementerios como herramientas de dominación social de forma clasista y discriminatoria, mencionando que..."Ios grandes mausoleos y las lujosas lapidas están separadas y sólo son usadas por la clase dominante, por aquellos que se pueden pagar una muerte rica"... (Aguilera y González, 2009, p. 6).

Retornado a Venezuela, Yuleima Rodríguez realizó una... "breve reseña de los cementerios de Caracas que antecedieron al camposanto del Sur"... (Rodríguez, 2011, p. 173). Siendo el Cementerio del Sur uno de los más reconocidos y llamativos para el estudio antropológico, gracias a su particular distribución y cambios sufridos durante los procesos históricos y sociales del país (transformaciones de las cuales advirtieron Zucchi (2000), Velásquez (2009) y Aguilera y González (2009), mencionados 
anteriormente) y siendo la necrópolis del Sur un intrigante espacio arqueológico, da paso también a reivindicaciones históricas y patrimoniales.

Siguiendo la línea venezolana, se encuentra el Cementerio de los Extranjeros de la Guaira, en Punta de Mulatos, población perteneciente a la Parroquia La Guaira del estado Vargas, donde una antropóloga venezolana se adentró en la arqueología de la muerte (Monroy, 2016, p. 23). En dicha pesquisa, se observa un objetivo similar al planteado por Zucchi (2000) respecto al estudio del contenido semiótico que se encuentra intrínseco en los camposantos, siendo en este trabajo realizado por Monroy, el simbolismo asociado a la masonería. A su vez, la autora expone cierta preocupación por la arqueología de rescate (Monroy, 2016, p. 23), pues la mencionada necrópolis se encuentra en riesgo de desaparecer debido a los procesos de levantamiento de infraestructuras comerciales y habitacionales que se están llevado a cabo en el estado Vargas. Monroy expresa también su preocupación por el daño que está siendo ocasionado a los viejos camposantos debido a los procesos urbanistas en la ciudad capital, advirtiendo que a raíz de la indiferencia y el imparable avance infraestructural, estos sitios terminan siendo demolidos y arrojados al olvido. Sin embargo, según la autora, en otras ciudades, estos antiguos lugares sagrados de descanso eterno..."fuera de la ciudad capital lograron "sobrevivir" hasta nuestros días"... (Monroy, 2016, p. 28).

De esta manera Flood (1991), Zucchi (2000), Velásquez (2009), Aguilera y González (2009), Rodríguez (2011) y Monroy (2016) contribuyen a lo planteado anteriormente sobre la representación de la muerte como elemento clave para la comprensión de las configuraciones sociales aportando elementos para el rescate socio-cultural y de tradiciones de individuos lamentablemente olvidados en el tiempo como los afrodescendientes.

\section{Osteología y cementerios}

Una vez expuestos abordajes osteológicos y diversas investigaciones en camposantos por separado, debemos retomar el rumbo de la osteología de rescate y la bioarqueología, lo que permite ubicar y presentar incursiones donde se realizaron directamente estudios en restos óseos provenientes de cementerios.

Iniciamos con Wright y su equipo, quienes elaboraron en Guatemala durante 1998, el abordaje de un contexto arqueológico en el sitio Kaminaljuyu, planteando una osteología de rescate para la preservación de los restos óseos que ahí se encontraban, siendo el objetivo principal del estudio recopilar datos sobre la dieta prehispánica. Para ello las piezas óseas fueron fundamentales, pues a través de un... "análisis químico de los huesos"... (Wright et al, 1998, p. 558) se determinaría la dieta que mantuvieron los individuos ahí enterrados.

Inmediatamente, descendemos hasta América del sur, específicamente en Chile donde se encuentra la población de Penco, lugar donde las investigadoras Guerra y Reyes (2012) realizaron una labor osteológica rescatista en el sitio Cementerio Parroquial de Penco, luego de un incidente 
desastroso a raíz de un terremoto. Las investigadoras justifican su investigación argumentando que... "los cementerios son reservorios de descanso y honra a los difuntos (...) [y] dejar de ir al cementerio significa el olvido de los difuntos"... (Guerra y Reyes, 2012, p. 4). Esta labor se realizó en conjunto con la Comunidad de Penco y estudiantes de Antropología de la Universidad de Concepción, tras efectuar la recolección, análisis e individualización de "51 individuos femeninos y 72 individuos masculinos, dando un total de 122 osamentas óptimas para su identificación" (Guerra y Reyes, 2012, p. 5). Esto trajo nuevamente la paz a los familiares pero también a los individuos que allí reposan. El abordaje osteológico y etnográfico realizado por el mencionado equipo, reveló a las autoridades de Chile..."la deficiencia de protocolos o metodologías antropológicas pre-existentes para la realización de un trabajo de gran impacto social" (Guerra y Reyes, 2012, p. 9) lo cual debería motivar a una mejor preparación por parte del gabinete gubernamental en materia antropológica y de osteología de rescate.

Nos alejamos geográficamente del continente americano, dirigiendo el rumbo hacia España, donde la primera investigación a ser presentada en materia osteológica, es la interesante labor realizada por Roca de Togores en el cementerio islámico de Bab Al-Hanax (España), en donde "Se han estudiado antropológicamente restos humanos (...) correspondientes a no menos de 75 individuos"... (Roca de Togores, 1999, p. 2). Esta investigación posee un enfoque de reconstrucción histórica y reivindicativa de la cultura islámica. La incursión de la mencionada autora reveló que la población estudiada pertenece a un grupo... "de restos óseos humanos de finales del siglo XII y principios del XIV"... (Roca de Togores, 1999, p. 2). Lo que ubica a este camposanto específicamente durante la ocupación de los árabes en la península Ibérica. Este estudio proporciona herramientas y métodos para el análisis de piezas óseas en un alto estado de degradación.

Del mismo modo, Amaia Mendizabal (2011) realiza un estudio en los cementerios Altomedievales del País Vasco afirmado que..."los huesos pueden proporcionar abundante información acerca de las sociedades humanas del pasado"... (Mendizabal, 2011, p. 403), demostrando el valioso e importante rol que juegan las piezas óseas dentro de un contexto investigativo de espacios funerarios. Esto coincide con lo dicho por Brothwell..."ninguna reconstrucción social puede considerarse completa sin un examen de la estructura física y la salud de la comunidad"... (1987, p. 7) y coincide así con los trabajos de Flood (1991), Zucchi (2000), Velásquez (2009), Aguilera y González (2009), Rodríguez (2011) y Monroy (2016).

\section{Osteología de rescate en estudios sobre poblaciones afrodescendientes}

Una de las primeras incursiones registradas en cementerios afrodescendientes, donde se puede apreciar el inicio de la aplicación de la osteología como disciplina auxiliar, fue en 1987 a cargo de los investigadores Owsley, Orser, Mann, Moore y Montgomery, quienes realizaron el abordaje al "First Cemetery of New Orleans", para ... "obtener información osteológica sobre la salud, 
el estado nutricional y las formas de vida de esta temprana población histórica de Nueva Orleans" (Owsley, Orser, Mann, Moore y Montgomery, 1987, p. 185). Un total de veintinueve osamentas fueron recuperadas, revelando importante información sobre los procesos de la esclavitud en la ciudad de Nueva Orleans, los mencionados autores exponen que su muestra estuvo conformada por..."un recién nacido lactante, 2 niños de 5 a 9 años, 3 adolescentes de 15 a 19 años y 23 personas mayores de 20 años. La categoría de edad más antigua representada es de 50 a 59 años." (Owsley, Orser, Mann, Moore y Montgomery, 1987, p. 188). Los investigadores señalan que la asignación racial únicamente pudo ser aplicada a quince individuos, de los cuales trece coincidieron con la afinidad racial negroide. Por otra parte, se confirmó que se trataba de una muestra de restos de antiguos esclavizados debido a la presencia de severas lesiones en el esqueleto post craneal y su desgaste dental. Este análisis contribuyó a realizar una comparación sobre los estilos de vida de los esclavizados en las ciudades y los que se encontraban en las plantaciones, arrojando que los citadinos sufrían de menos abusos y desgaste que los condenados al arduo trabajo de la producción de la tierra. Este estudio representó un gran aporte a la reconstrucción de la historia de la esclavitud en Estados Unidos y a la reivindicación que merecen los esclavizados, quienes en muchos casos y por largos periodos de tiempo, fueron ignorados y omitidos de los registros históricos.

Seguidamente, Ross Jamieson, realizó un estudio sobre los tipos de enterramientos afroamericanos (Jamieson, 1995, p. 39) basado en el reconocimiento de patrones de sepultura y el desarrollo de herramientas identificativas para comprender el contexto funerario en su totalidad, pues el mencionado autor advierte que el... "interés arqueológico en patrones mortuorios ha crecido para incluir estatus individual, modos de muerte, ritos de paso, afiliaciones grupales y muchos otros tipos de información cultural" (Jamieson, 1995, p. 40), expandiendo de esta manera el rango de interés y de acción de las ciencias sociales. En el mismo orden de ideas, el mencionado autor otorga una pequeña guía para el reconocimiento y ubicación de los camposantos en los territorios que se presumen están presentes las sepulturas afro-americanas..."Esta identificación se puede hacer utilizando material cultural asociado al fallecido, utilizando evidencia histórica acerca de un cementerio afro-americano en la localidad, o mediante la identificación física, (...), es decir, usando técnicas osteológicas" (Jamieson, 1995, p. 44). Es importante destacar que en la intervención arqueológica realizada por Jamieson y su equipo de trabajo no se analizaron los restos óseos para complementar el estudio que se estaba realizando, pues únicamente se contemplaron elementos de cultura material asociados a los enterramientos. Asimismo, Jamieson reconoce la responsabilidad que recae sobre los estudios osteológicos y afirma que... "Ios restos osteológicos pueden ser la única manera de identificar el cementerio como un cementerio afro-americano sin dependencia de las prácticas culturales" (Jamieson, 1995: 46).

Siguiendo la línea geográfica-temporal, se encuentra la investigación a cargo de la Chicora Foundation, sobre la importancia de preservar viejos cementerios afro-americanos correspondientes a las antiguas plantaciones de la costa sureste de Estados Unidos, específicamente en Carolina del Sur, donde los autores de este magnífico abordaje indican que... "los restos fueron excavados 
para el estudio y posterior re-entierro (...) y este estudio ayudó a confirmar lo que conocemos históricamente y ha añadido mucho a nuestro conocimiento de la dieta y las enfermedades afroamericanas"... (Chicora Foundation, 1996, p. 8-9). Por lo tanto, en este trabajo sí fueron analizadas las piezas óseas extraídas de las excavaciones efectuadas en el camposanto denominado "38CH778" (Chicora Foundation, 1996, p. 8). Estos análisis de los restos óseos tuvieron resultados imponentes, ya que arrojaron pruebas de malas condiciones de vida, mostrando evidencias de estrés ocupacional tanto en hombres como en mujeres, y un severo trauma alimenticio proveniente desde la infancia (Chicora Foundation, 1996, p. 9). Debido a esta clase de evidencias, la Fundación Chicora, INC, revela sin lugar a dudas las extremas condiciones de vida y la explotación que esos individuos tuvieron que sobrellevar en las plantaciones norteamericanas (Chicora Foundation, 1996, p. 9). Resulta fundamental decir que no sólo en Norteamérica, sino en todas las investigaciones de necrópolis donde reposan los restos de aquellos que alguna vez sufrieron el régimen esclavista impuesto por los europeos y su trasladado hacia las colonias americanas, los... "viejos cementerios afroamericanos rara vez están documentados, aparecen con poca frecuencia en los mapas y casi nunca se muestran en documentos históricos. Simplemente no era importante para los propietarios de las plantaciones mostrar la ubicación del cementerio esclavo." (Chicora Foundation, 1996, p. 10). Este estudio encuentra puntos en común con el que fue realizado por Wright (1998), aun cuando se trata de afinidades raciales distintas, pues los resultados arrojaron datos muy similares revelando la importancia de las piezas óseas para entender con mayor profundidad el contexto en el que vivían los individuos en cuestión.

Descendiendo abruptamente desde Carolina del Sur hacia el Mar Caribe y ubicándose en la misma línea temporal, se encuentra el revelador estudio de Jerome Handler, realizado en la isla de Barbados, específicamente en el cementerio de Newton, el cual posee una característica diferencial con respecto a otros camposantos, y es que este cementerio se encuentra documentado en los archivos de la nación (Handler, 1997, p. 93). Handler advierte que "La investigación arqueológica (...) se centró en un cementerio de esclavos en Newton, una plantación de raíces profundas en el siglo XVII"... (Handler, 1997, p. 10). Aun cuando durante el abordaje de Handler una buena porción de la necrópolis de Newton en la isla de Barbados fue intervenida, en principio se lograron extraer sólo noventa y cuatro individuos, y luego de ser efectuados los análisis pertinentes, los resultados arrojaron que en realidad eran ciento cuatro osamentas y que... "estos 104 individuos fueron enterrados desde alrededor de 1660 a 1820"... (Handler, 1997, p. 93). Sin embargo, el mencionado autor centró parte del estudio en lo que él y su equipo denominaron como el Entierro 72 (Handler, 1997, p. 98), una osamenta que presentó características diferentes con respecto a las demás, pues esta sería la única sepultura con restos de cultura material asociadas al contexto arqueológico. La presencia de estos elementos motivó a Handler a entender la posible existencia de ciertas jerarquías dentro de los grupos de los esclavos.

El abordaje del Enterramiento 72 consistió en la extracción y análisis osteológico craneal y post-craneal de un esqueleto que se encontraba sepultado con poca profundidad y así menciona 
Handler, "el cráneo se encontraba únicamente a ocho centímetros de la superficie, mientras que sus pies se encontraban a dieciséis centímetros por debajo." (Handler, 1997, p. 98).

Esta investigación reveló cierto grado de facilidad para la ubicación e intervención de los yacimientos cuando se encuentran registrados en la documentación oficial, además de la apertura de una nueva hipótesis sobre un sistema jerárquico dentro de los grupos esclavizados en el Caribe.

Volviendo a tomar el rumbo geográfico hacia el Norte del continente, se encuentra Charles Orser en Estados Unidos, autor que incursionó en el área de arqueología de la diáspora africana, donde realiza estudios a profundidad en el ámbito del racismo y de la arqueología histórica. Asimismo, menciona directamente que los objetivos de su investigación se inscriben en el desarrollo de... "la arqueología de la identidad cultural, los aspectos materiales de la libertad de la esclavitud, y la examinación arqueológica de la raza." (Orser, 1998: 63). El citado autor en su despliegue interdisciplinario, encamina su investigación hacia el tema socio-político del nacionalismo y menciona que en el contexto afro-americano, puede llegar a ser usado como una herramienta para la reivindicación de las personas que se reconocen como afrodescendientes, pues advierte que "El papel del arqueólogo en la sociedad en general se ha convertido en un tema importante de investigación, en particular cuando se trata de nacionalismo y el uso de restos arqueológicos para la construcción de la identidad nacional" (Orser, 1998, p. 76), Del mismo modo, Orser ha estado involucrado en otro tipo de incursiones, tal y como se mencionó anteriormente en su trabajo en conjunto con Owsley, Mann, Moore y Montgomery en la ciudad de Nueva Orleans.

Seguidamente, en Brasil se observa el trabajo de Ana Mansilla Castaño, con una propuesta similar a la de Handler de 1997. Mansilla Castaño incursiona en el área temática definida por ella como arqueología afro-americana (Mansilla Castaño, 2000, p. 2), y explica que se trata de un... "estudio arqueológico del pasado de la población americana de origen africano, principalmente los esclavos de las plantaciones y sus descendientes libres o no" (Mansilla Castaño, 2000, p. 2). Sin embargo, dentro de esta arqueología afro-americana, Mansilla Castaño otorga otro término para su estudio, gracias a la especificidad del territorio que fue trabajado, siendo el título oficial asignado: arqueología de los quilombos (Mansilla Castaño, 2000, p. 3). En conjunto con la introducción de esta terminología, Castaño realiza una reflexión análoga a la realizada por Orser (1998) con respecto al uso de la arqueología como refuerzo para el discurso político-nacionalista orientado hacia la reivindicación del sentimiento afro-americano. Al respecto Mansilla Castaño señala entonces que:

La arqueología de los quilombos tiene un importante papel político al rescatar el pasado de la etnia negra marginada en Brasil y romper con el monopolio blanco en la preservación del patrimonio. Es decir que el patrimonio material que se estudia, se preserva y se divulga ya no es sólo el de la cultura y el pasado de la población blanca (Mansilla Castaño, 2000, p. 3). 
Trabajos como éste permiten a la población una mejor comprensión de sus orígenes, y se encaminan hacia una aceptación y una reivindicación de los grupos étnicos marginados. Las intervenciones arqueológicas efectuadas por Mansilla Castaño y su equipo, se efectuaron ente 1992 y 1993, en el estado de Alagoas, específicamente en la Serra da Barriga perteneciente al Municipio de Uniao dos Palmares.

Advierte Mansilla Castaño que... "Se identificaron catorce yacimientos y se recogieron casi 2500 artefactos" (Mansilla Castaño, 2000, p. 8), de los cuales fueron en su mayoría de tipo cerámico. En esta pesquisa no fueron recolectadas ni utilizadas las piezas óseas de los yacimientos abordados, pues esta incursión se vio centrada en el análisis de la cultura material recuperada de las sepulturas. Gracias a este estudio por parte de la mencionada autora y otras incursiones en el área, en Brasil se logró una pequeña inclusión de los grupos segregados afrodescendientes. Se incluiría por primera vez en los libros de texto a la población negra como parte de la construcción histórica de la nación, pues lo que no se encuentra plasmado en papel y publicado no puede ser conocido, es realmente inexistente. (Mansilla Castaño, 2000, p. 11).

Posteriormente, Orser y Funari presentan su trabajo de investigación arqueológica sobre la esclavitud del Brasil, enmarcado en un horizonte más vasto pues: "La arqueología de la resistencia esclava y la rebelión se desarrolló como parte del proyecto más amplio para comprender la experiencia de la diáspora africana" (Orser y Funari, 2001, p. 62), lo cual demuestra que el estudio de los cementerios afrodescendientes o afro-americanos, no sólo debería contemplar su intervención para extraer cultura material o piezas óseas, sino que también debe examinar la situación socio histórica de los esclavos en el pasado y la situación actual de su descendencia.

Consecutivamente se encuentra el abordaje presentado por Blakey y Rankin-Hill, quienes en el 2004 revelaron en conjunto con su equipo, el informe final de varios años de trabajo en el Cementerio Afro-Americano de Nueva York. Este proyecto tuvo como objetivo de estudio cuatro variables principales... "orígenes, la vida cotidiana, la resistencia a la esclavitud, y el desarrollo de las identidades afro-americanas" (Blakey y Rankin-Hill, 2004, p. 10), para lo cual se requirió de un equipo interdisciplinario especializado ya que se realizaron exámenes biológicos y antropológicos a los restos óseos, mientras que también fueron ejecutadas pruebas genéticas, las cuales se cruzaron con estadísticas poblacionales. La mencionada investigación también entrelazó intereses con lo señalado por Mansilla Castaño (2000), Zucchi (2000), King (2010) y demás autores citados, pues gracias a este trabajo presentado por Blakey y Rankin-Hill (2004) se..."crearía un plan para aprender acerca de las personas que utilizan el cementerio Afro-Americano de Nueva York y cómo y cuándo se utilizó." (Blakey y Rankin-Hill, 2004, p. 6). Este trabajo logró el interés y el seguimiento de la investigación por parte de los pobladores afro-americanos de la ciudad de Nueva York, lo cual reflejan los autores diciendo que..."la comunidad descendiente quería respuestas a través del estudio"... (Blakey y Rankin-Hill, 2004, p. 10).

Este proyecto que tuvo inicio en el año 1991 y finalizó diez años más tarde, es uno de los más arduos que se hayan llevado a cabo en materia antropológica en Nueva York, siendo la 
osteología de rescate el desafío emergente en la década cuando comenzó el estudio. Luego de tantos años, estos fueron los objetivos propuestos y cumplidos por los mencionados investigadores y su equipo de trabajo:

(1) Establecer un museo para conmemorar el cementerio africano como un punto de referencia nacional, (2) erigir un monumento dentro del área de interés, (3) desarrollar signos que interpreten la historia y la cultura de los africanos en el área de interés, (4) instalar y exhibir una obra conmemorativa en el vestíbulo del edificio de oficinas. (Blakey y Rankin-Hill, 2004, p. 6).

En el mismo orden de ideas, aun cuando Blakey y Rankin-Hill no utilicen el término osteología de rescate, todo su trabajo hace referencia a la necesidad y la importancia del rescate osteológico luego de haber intervenido un yacimiento donde fueron analizadas y procesadas más de quinientas osamentas. Blakey y Rankin-Hill advierten sobre una realidad que es de suma relevancia: "Muchos esclavos africanos fueron transportados al Caribe antes de ser enviados a Nueva York, por lo que la experiencia de los esclavos africanos debe ser estudiada en el Caribe también." (Blakey y Rankin-Hill, 2004, p. 8), lo cual puede considerarse una invitación a repetir esta clase de investigaciones ya enfocándose en el tránsito de esclavos desde el Caribe hasta que llegaron definitivamente a New York, pues muchos fallecieron en estos territorios caribeños como resultado de las pésimas condiciones de traslado que venían padeciendo desde que fueron cazados en África. De allí el llamado de Blakey y Rankin-Hill.

Inmediatamente en Estados Unidos, la investigadora Charlotte King realizó un estudio sobre los cementerios en New Philadelphia en el estado de Illinois. La citada autora durante sus indagaciones en la localidad mencionada, encontró que... "Los residentes de New Philadelphia utilizaban dos cementerios, uno que servía principalmente a familias afro-americanas, y uno que sirvió a estadounidenses descendientes de europeos." (King, 2010, p. 125). Posteriormente King aborda un enfoque muy similar al expuesto por Castaño (2000) y Zucchi (2000), resaltando que... "para los esclavos africanos y los afro-americanos, los cementerios tenían un significado especial. Los cementerios representan el dominio de los difuntos, y un lugar para expresar las identidades culturales dentro de las diásporas africanas"... (King, 2010, p. 125). Al mismo tiempo afirma que los cementerios eran uno de los pocos lugares donde los esclavizados podían expresar sus creencias religiosas y podían relacionarse entre ellos ya que los capataces de otras plantaciones vecinas o en locaciones cercanas, también otorgaban jornadas libres para que los individuos pudiesen asistir a las ceremonias y rituales de enterramientos. (King, 2010, p. 126). Durante las jornadas de intervención y recolección de datos in situ, King advierte el hecho de que..."ninguna excavación arqueológica invasiva fue requerida"... (King, 2010, p. 131), debido a que los enterramientos se encontraban visibles y bien identificados. King explica este fenómeno gracias a que la ubicación del cementerio utilizado para la inhumación de los individuos esclavizados estaba registrado en los archivos de la plantación y de la nación, pues este camposanto entró en labor en 1851 y es el lugar donde descansa 
Frank McWorter, el primer hombre afro-americano en fundar y registrar un poblado en Estados Unidos, siendo por ello que esta necrópolis no se perdió en el tiempo ni en las memorias de los locales. (King, 2010, p. 134).

\section{Osteología de rescate en el antiguo cementerio de Todasana}

Finalmente, el autor de estas palabras incursionó entre 2016 y 2019 en el ámbito de la osteología de rescate y la bioarqueología, en la comunidad de Todasana, ubicada en la parroquia Caruao del estado Vargas, Venezuela ${ }^{3}$. Se trata de una pequeña comunidad afrodescendiente perteneciente al litoral central del país, en donde a través de los registros históricos obtenidos por la investigadora Yara Altez (1999), se pudo evidenciar la presencia y el funcionamiento de una hacienda cacaotera trabajada bajo el régimen esclavista de producción.

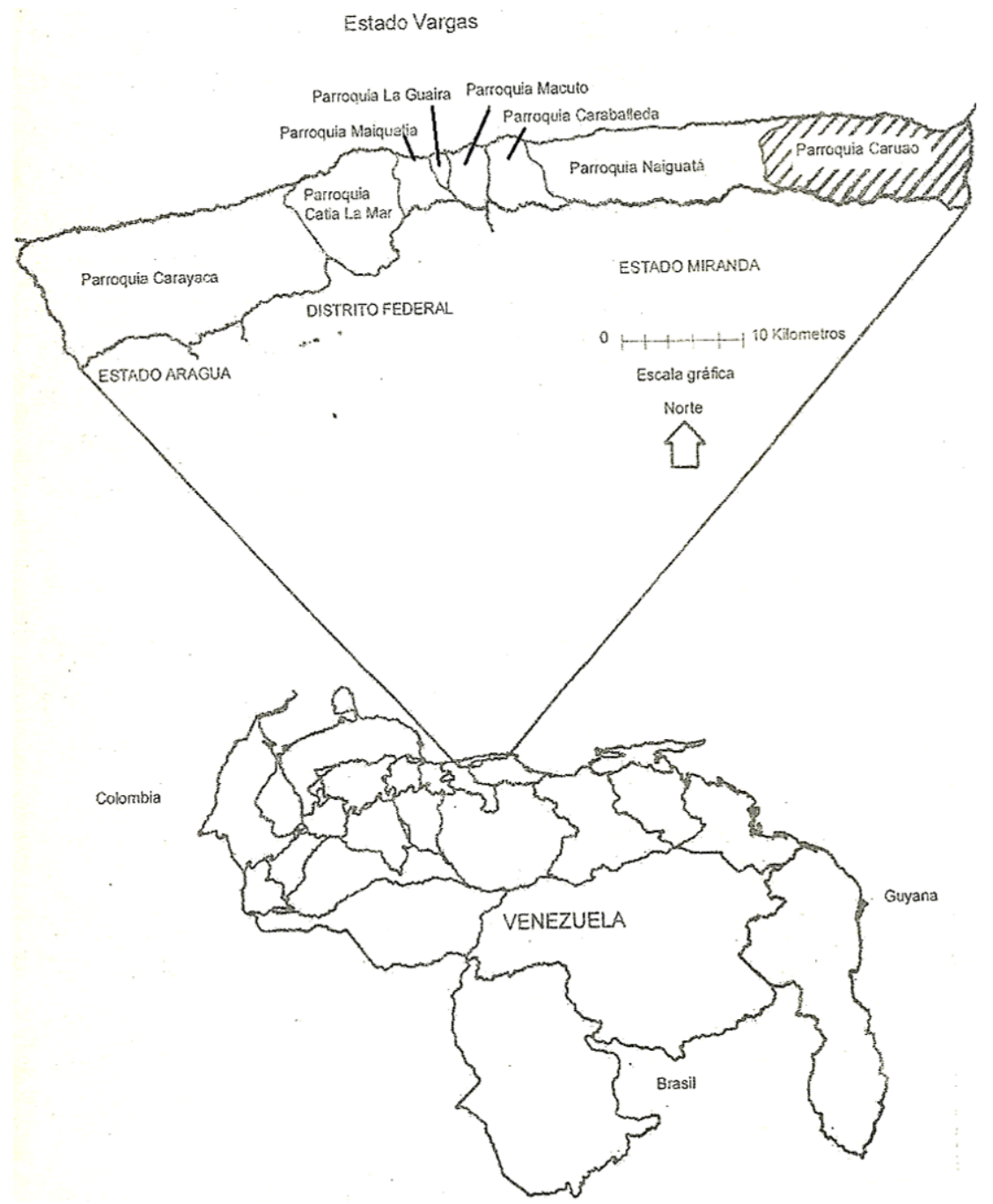

Mapa 1. Ubicación de la parroquia Caruao en el contexto de Venezuela. Señalando la parroquia Caruao con círculo. Extraído de Altez y Rivas (2002, p.14).

\footnotetext{
3 En los Mapas 1, 2 y 3 se puede observar la ubicación de la comunidad de Todasana.

PÉREZ, Antonio David. La investigación antropológica y osteológica en cementerios afrodescendientes. Cadernos do Lepaarq, v. XVI, n.33, p. 126149, Jan-Jun. 2020.
} 


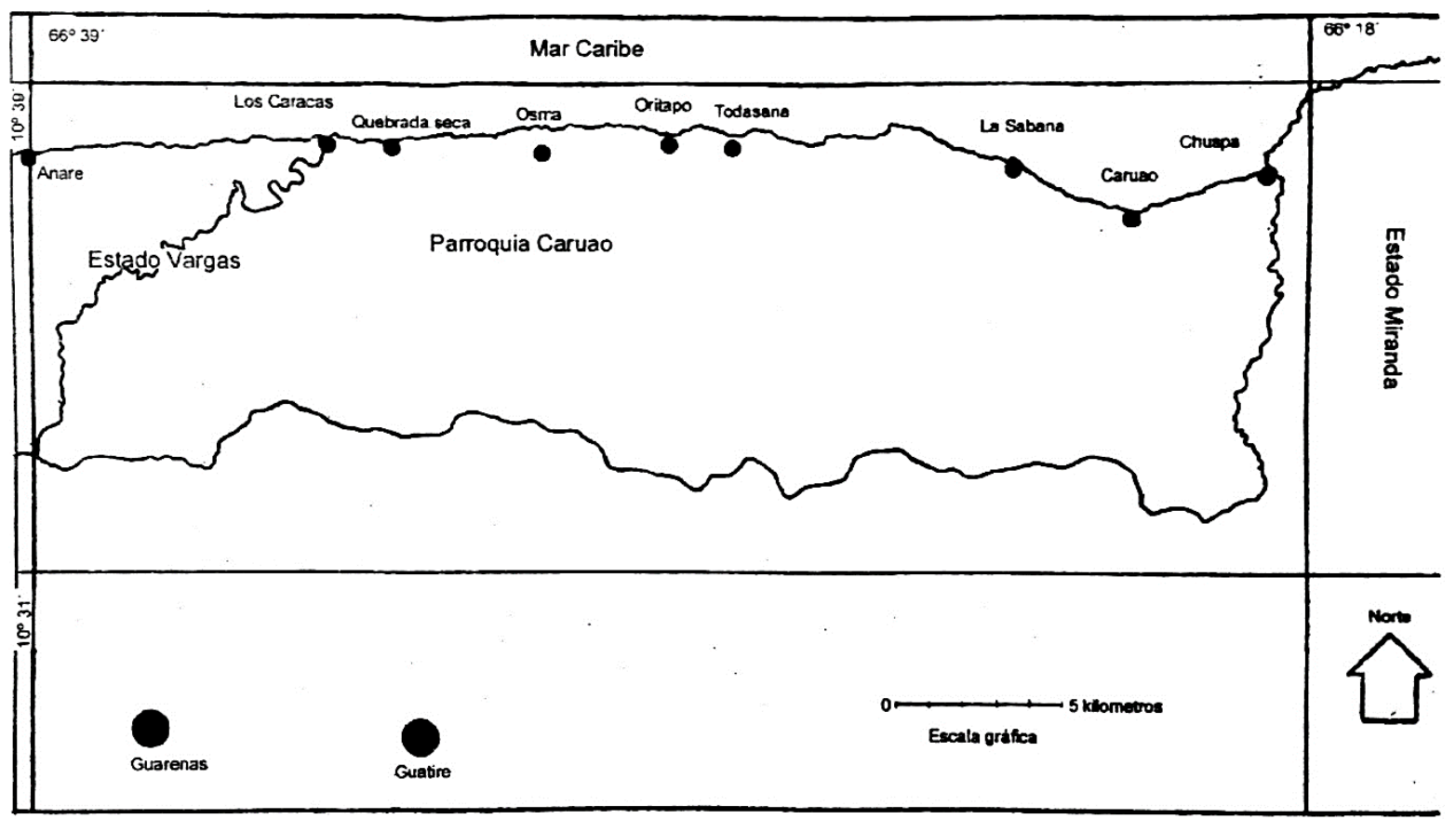

Mapa 2. Ubicación de Todasana en el contexto de la Parroquia Caruao. Señalando la comunidad de Todasana con un círculo. Extraído de Altez y Rivas (2002, p.15).

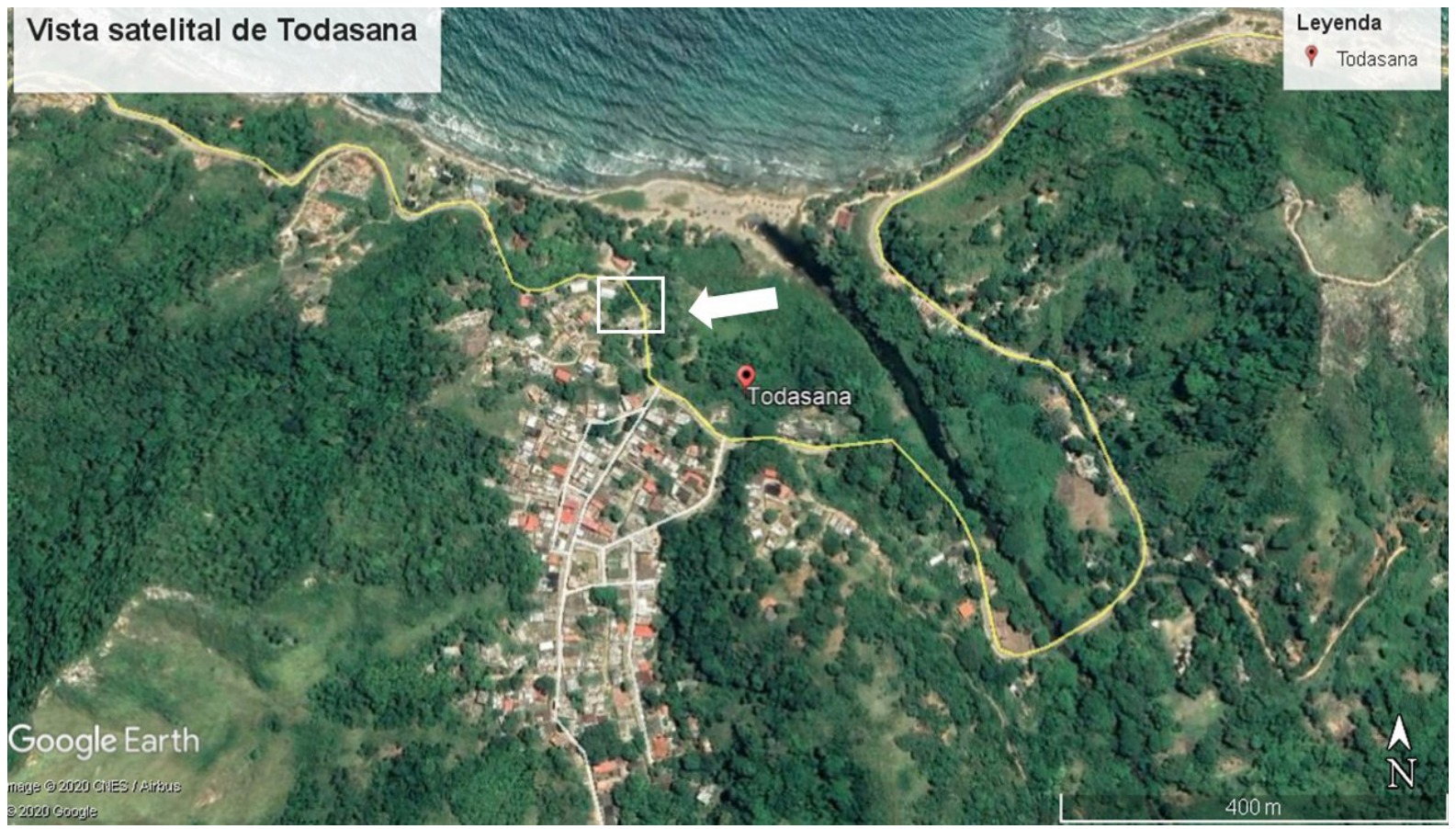

Mapa 3. Vista satelital de Todasana. Obtenido con Google Earth en 2020. Se señala (en color blanco) con una flecha y un recuadro la ubicación del Antiguo Cementerio de Todasana.

En la mencionada comunidad se encuentra un antiguo y abandonado cementerio ubicado en una loma y al borde de un pequeño desfiladero originado por la acción de una pala mecánica 
a principios de los años 60 del siglo XX, que tenía como objetivo la apertura de una carretera que comunicase a las 6 comunidades de la Parroquia Caruao entre ellas y con el resto del país4.

El cementerio es uno de los primeros lugares que pueden ser observados al arribar a Todasana, pero por lo general se encuentra cubierto totalmente de maleza, tal como se quiere mostrar en la imagen siguiente. Este sitio esconde un gran significado histórico y patrimonial a pesar de su crítica condición de abandono y descuido generada por la fría indiferencia de sus habitantes. Curiosamente, la memoria oral reconoce a los inhumados en este sitio como "los antiguos" (Altez, 2008 , p. 270) quienes posiblemente en antaño y desde el siglo XVII fueron aquellos sometidos al régimen de producción esclavista venezolano, en la que se llamó desde entonces Hacienda Todasana.

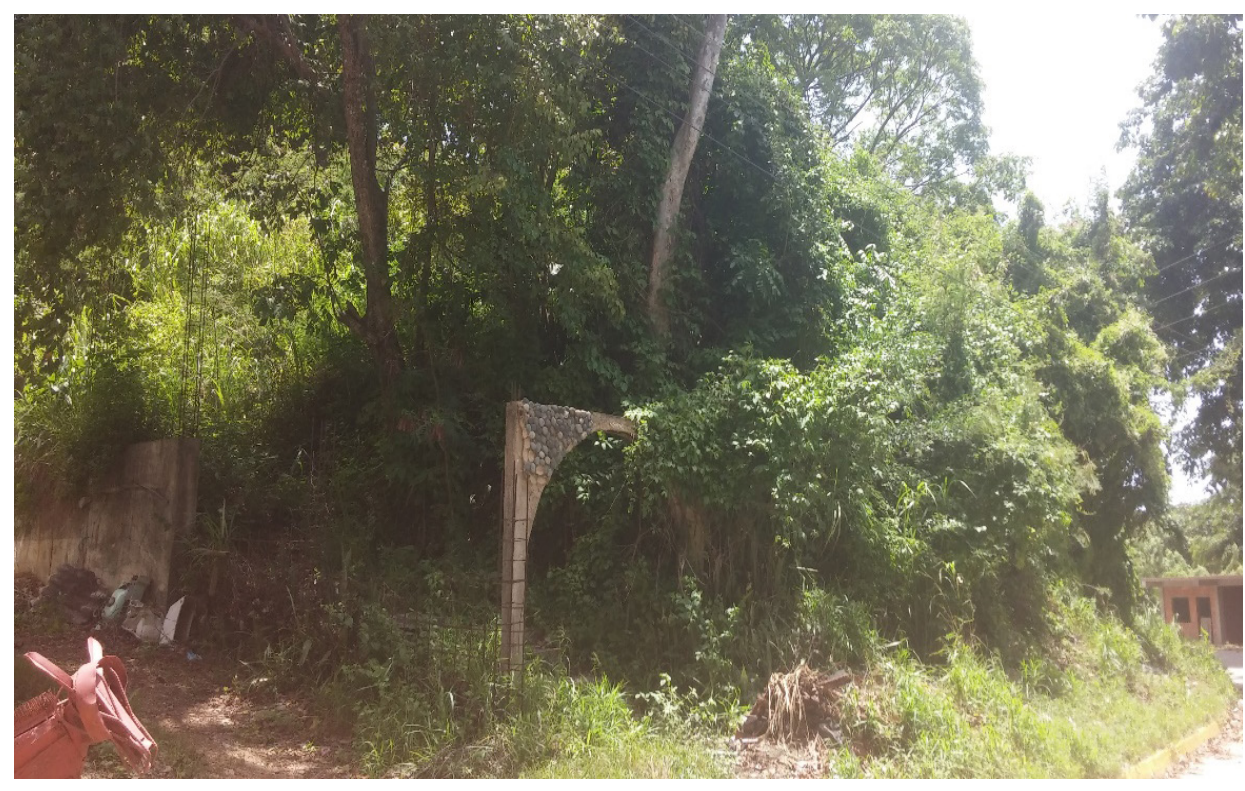

Figura 1. Entrada del Antiguo Cementerio de Todasana en 2016.

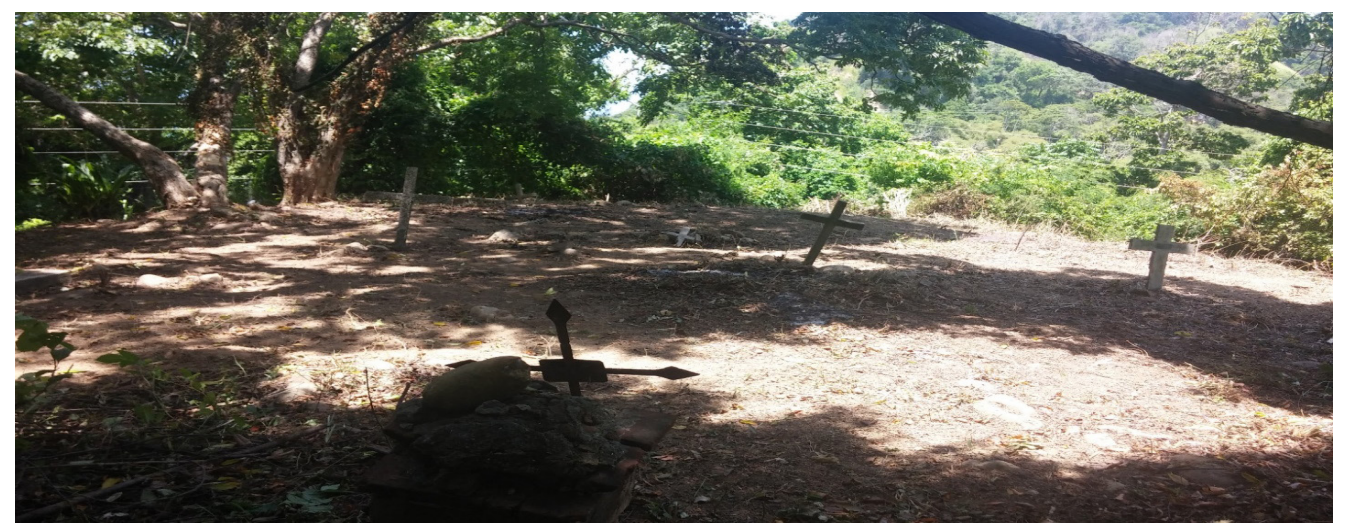

Figura 2. Vista general del Antiguo Cementerio de Todasana en 2016 posterior a una limpieza efectuada a propósito de la investigación que se hiciera.

A través de la osteología y la arqueología de rescate, se intentó obtener una muestra de restos óseos de aquellos quienes pudieron haber sido los esclavizados de la antigua Hacienda

\footnotetext{
${ }^{4}$ La apertura de una carretera respondió a la necesidad de los habitantes de estas comunidades quienes tradicionalmente solían caminar desde sus localidades hasta los centros poblados más cercanos, en este caso Los Caracas o Naiguatá. Dependiendo de la época, estas jornadas peatonales podían tomarles horas o días inclusive.
} 
Todasana. El objetivo más ambicioso de esta incursión fue extraer y analizar esa muestra bajo el lente de la antropología física, realizando una reconstrucción osteobiográfica, evaluando las cuatro variables clásicas de estudio: Afinidad Racial, Sexo, Edad y Estatura, así como los posibles marcadores de estrés ocupacional.

Para la obtención de las piezas que pretendían ser analizadas, se llevó a cabo una jornada de excavación que contempló la intervención del Antiguo Cementerio de Todasana, lo que llevó al investigador a realizar en primera instancia una planimetría para familiarizarse con el terreno y delimitar el espacio del yacimiento ${ }^{5}$. Seguidamente se presentó el proyecto de investigación a la comunidad con el objeto de obtener su aprobación ${ }^{6}$ y consecutivamente se procedió a iniciar las excavaciones.

Primeramente, fueron ubicadas y excavadas cuatro (4) calicatas de sondeo de 50x50 cm cada una, que posteriormente se expandieron a pozos de sondeo con dimensiones mayores, hasta alcanzar el metro de profundidad y anchos de 2 y 1,5 metros en los pozos 1 y 2 respectivamente, a diferencia de los pozos 3 y 4 que se mantuvieron en $1 \times 1$ metro. Tanto las calicatas como los pozos fueron decapados en niveles de $10 \mathrm{~cm}$ cada uno, para controlar de mejor manera el material encontrado. Los pozos eran profundizados hasta que no se evidenciase la presencia de material o hasta que el sitio no permitiese la continuidad de la excavación.

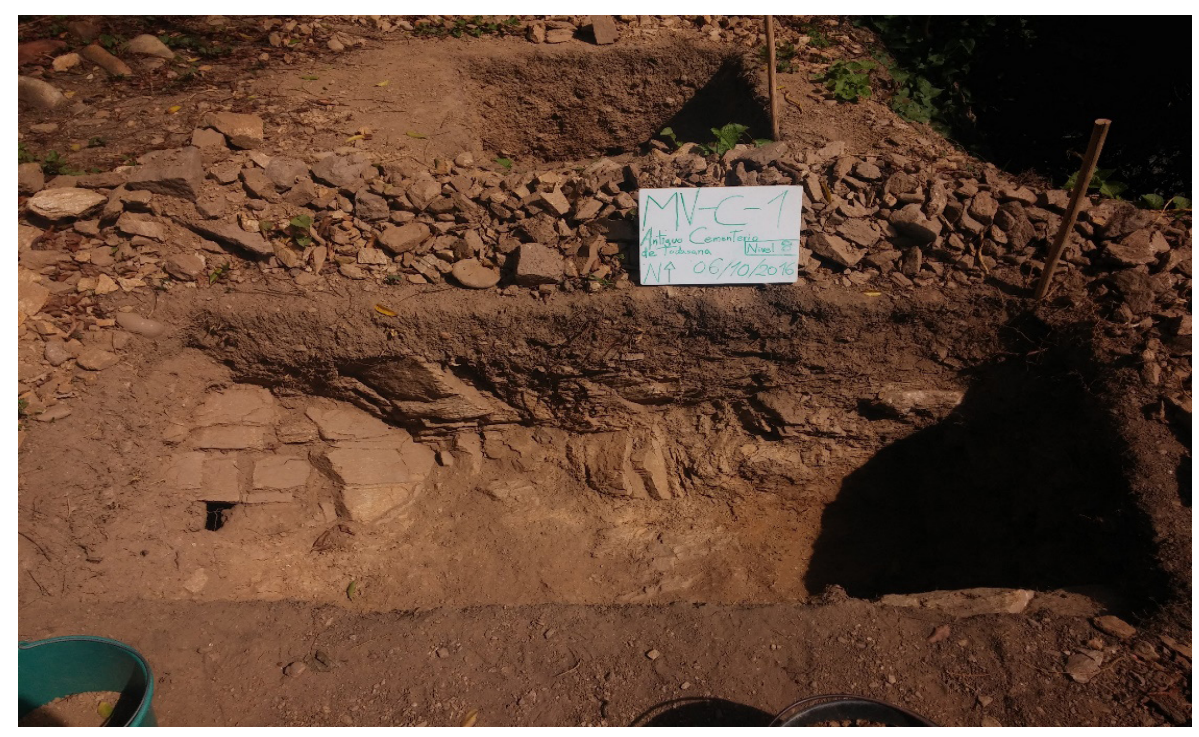

Figura 3. Exposición del fondo rocoso del Pozo 1 en el nivel 8 ( $80 \mathrm{~cm}$ de profundidad), del lado derecho se puede observar el desfiladero y en dirección norte puede apreciarse el Pozo 2.

\footnotetext{
5 Los alrededores del Antiguo Cementerio fueron objeto de dos sondeos arqueológicos realizados por Altez y Rivas a finales del siglo XX y a principios del XXI.

6 La comunidad de Todasana aprobó la intervención del camposanto siempre y cuando no fueran tocados los espacios que se encontraban identificados como enterramientos, es decir, los que presentases cruces, lo que llevó al investigador a sectorizar el yacimiento para su intervención.

7 La presencia de grandes rocas impedían la profundización de los pozos de sondeo a más de 1 metro de profundidad. 
Todos los pozos se encontraron en espacios cercanos al desfiladero mencionado anteriormente y respetando lo dicho por la comunidad sobre los espacios de excavación. En efecto, se acordó no intervenir lugares que estuvieran identificados como tumbas, por lo cual se trabajó en terreno sin cruces, muy cerca del borde desfiladero del antiguo cementerio.

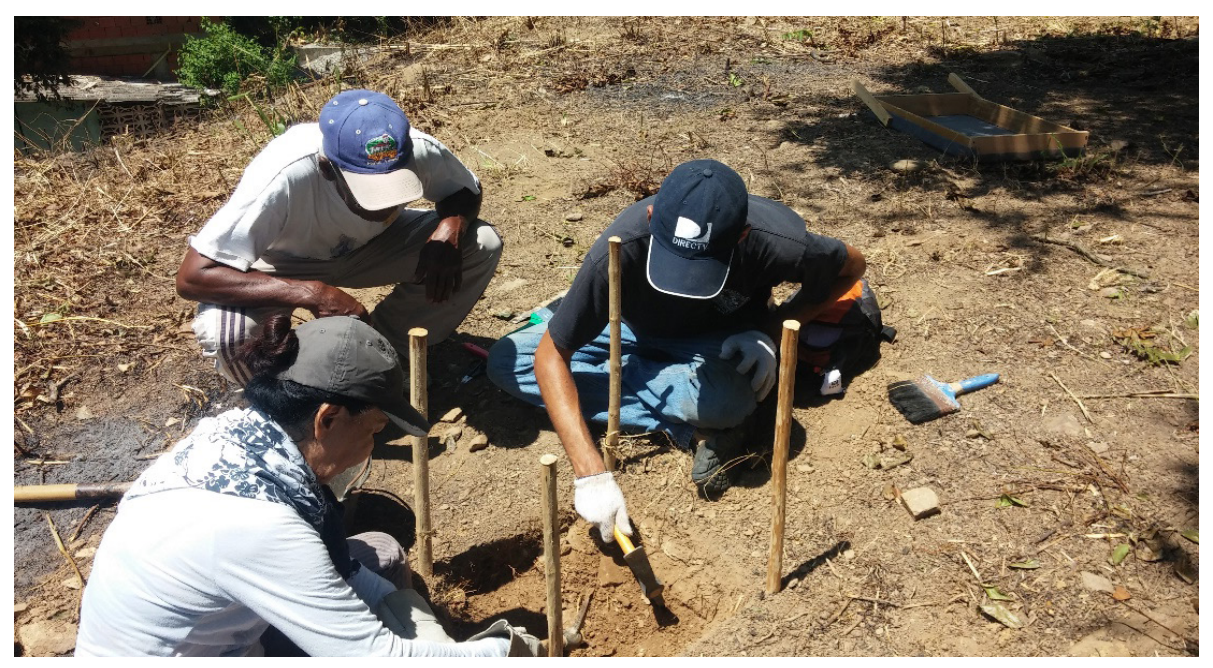

Figura 4. Proceso de decapado en el Antiguo Cementerio de Todasana, en la fotografía se aprecia a la Dra. Yara Altez, al señor $\mathrm{SS}^{8}$, miembro de la comunidad y al investigador Antonio Pérez.

Se excavó y analizó una muestra total de 1218 elementos, de los cuales 590 pertenecían a restos óseos del esqueleto craneal y post-craneal, en fragmentos de diversas dimensiones y proporciones. Sin embargo, todas estas piezas fueron halladas en paupérrimas condiciones, lo que lamentablemente impidió la aplicación de metodologías clásicas de estudio ${ }^{9}$. Además del estado en el que se encontraron estas piezas, su distribución no concordaba con la posición ordinaria en la que usualmente se disponen los restos, es decir la posición anatómica. Los restos óseos se encontraban de manera caótica, lo que daba para pensar que algo había ocurrido, y que quizás la apertura de la carretera estuviese involucrada.

\footnotetext{
${ }^{8}$ Se ha optado por no revelar el nombre de los colaboradores locales por respeto y salvaguarda de su identidad.

${ }^{9}$ Asignación de la afinidad racial y el sexo, estimación de la edad y estatura.
} 


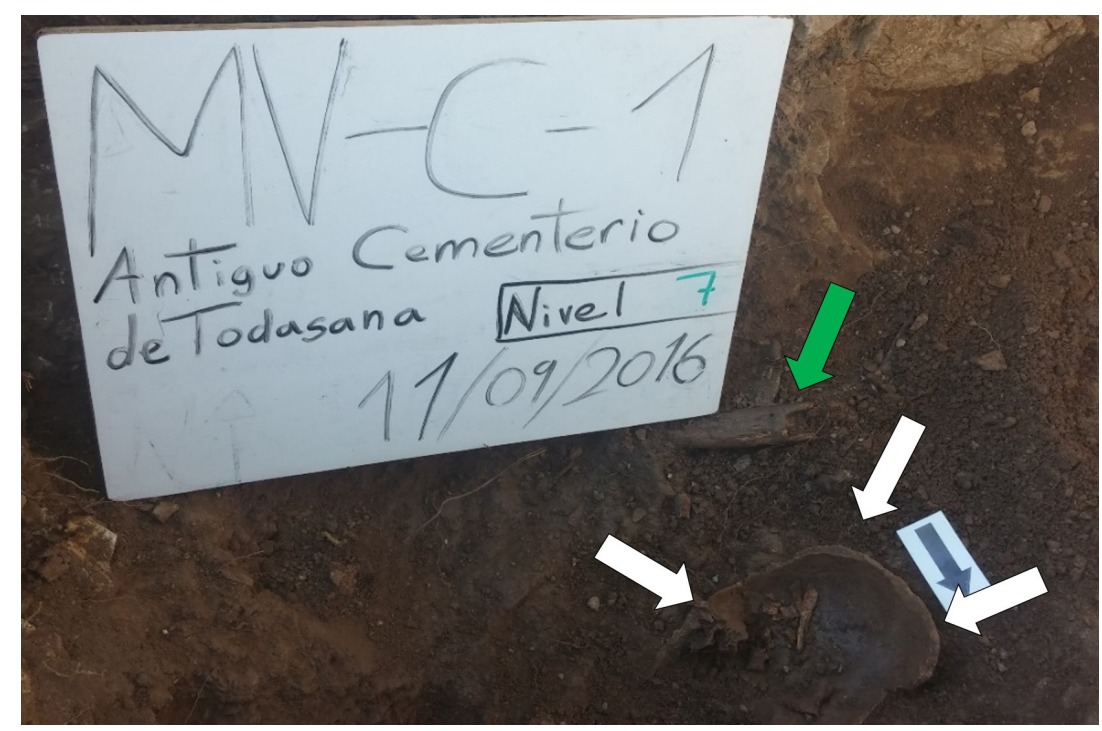

Figura 5. Exposición de restos óseos hallados en el Pozo 1, Nivel 7. Se observan fragmentos de esqueleto craneal y postcraneal acompañados de una flecha azul apuntando el Norte. Se señala con flechas blancas los restos del esqueleto craneal y con una verde los restos del esqueleto post-craneal. Tomada por Antonio Pérez el 11-09-2016.

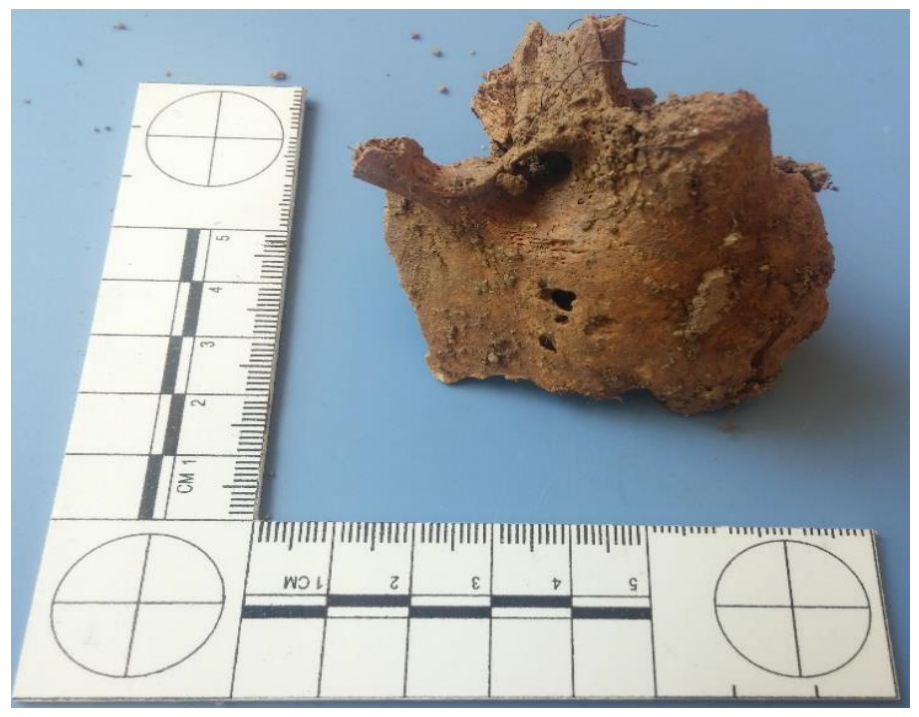

Figura 6. Exposición de fragmento del hueso temporal izquierdo de un cráneo excavado del Pozo $\mathrm{N}^{\circ} 1$. Tomada por Antonio Pérez el 07-10-2016.

Las piezas obtenidas presentaron un crítico estado de erosión y mineralización, lo cual ocasionó que no fueran aptas para análisis moleculares, pues su composición bioquímica original se encuentra completamente alterada, lo cual compromete la asertividad de los resultados.

Esta compleja situación devino en nuevas interrogantes y hallazgos, que solo pudieron ser entendidos y explicados a través de la tafonomía, disciplina que Sánchez Marcos define como "el estudio de la suerte habida por los restos de los organismos después de la muerte" (2009, p. 83) y al mismo tiempo señala que se trata de todos los... "cambios que repercutirán en el estado en 
que se hallen los restos" (2009, p. 83), exponiendo claramente un concepto sobre qué es el proceso tafonómico. En este mismo orden de ideas cabe destacar que los cambios pueden ser ocasionados por factores provenientes de dos vertientes: causadas por el medio ambiente (naturales) o por la intervención humana (antrópicos).

Los dos tipos de factores mencionados anteriormente intervinieron sobre el Antiguo Cementerio de Todasana, generando así su condición actual. La razón principal del mal estado de las piezas recuperadas en la excavación, se debe a la acción de la pala mecánica que intervino el cementerio en 1962 para construir la carretera del lugar. De esa forma se destruyó buena parte del sitio. Una eventualidad similar también se evidenció en la memoria oral de los vecinos de la comunidad de Todasana quienes hoy no guardan recuerdos de los antepasados allí enterrados (Altez, 1999; Pérez, 2019).

Para mejor entendimiento de cuáles son los factores y cómo influyeron sobre los restos óseos del cementerio antiguo de Todasana, se presenta a continuación la siguiente tabla:

\begin{tabular}{|c|c|c|c|}
\hline $\begin{array}{l}\text { Tipo de factor } \\
\text { tafonómico }\end{array}$ & $\begin{array}{l}\text { Sub-tipo de factor } \\
\text { tafonómico }\end{array}$ & $\begin{array}{c}\text { Daños observados en } \\
\text { las piezas }\end{array}$ & $\begin{array}{c}\text { Origen asociado al } \\
\text { factor }\end{array}$ \\
\hline \multirow[b]{2}{*}{ Antrópico } & Social & $\begin{array}{l}\text { Precario estado de } \\
\text { conservación }\end{array}$ & $\begin{array}{l}\text { Olvido, indiferencia } \\
\text { y abandono de los } \\
\text { restos óseos y del } \\
\text { antiguo cementerio. }\end{array}$ \\
\hline & Físico & \multirow[b]{2}{*}{ Severa fragmentación } & $\begin{array}{l}\text { - Intervención, } \\
\text { remoción y } \\
\text { reposición del } \\
\text { material con una pala } \\
\text { mecánica. }\end{array}$ \\
\hline \multirow{3}{*}{ Natural } & Biológico & & $\begin{array}{ll}\text { - } & \text { Descomposición } \\
\text { natural del organismo } \\
\text { post-mortem. } \\
\text { - Transcurrir del } \\
\text { tiempo. } \\
\end{array}$ \\
\hline & Químico & Mineralización & $\begin{array}{l}\text { Descomposición } \\
\text { del organismo, } \\
\text { reemplazo de la } \\
\text { materia orgánica con } \\
\text { mineral del suelo } \\
\text { donde se encuentra } \\
\text { inhumada. }\end{array}$ \\
\hline & Físico - Climático & Erosión & $\begin{array}{l}\text { - Remoción del suelo } \\
\text { como consecuencia } \\
\text { de la acción de la } \\
\text { pala mecánica. } \\
\text { - Condiciones } \\
\text { climáticas. }\end{array}$ \\
\hline
\end{tabular}

Tabla 1. Factores tafonómicos influyentes en el deterioro del Antiguo Cementerio de Todasana. (Extraído de Pérez, 2019, p. 186) 


\section{REFLEXIONES FINALES}

La reconstrucción de la historia de los esclavizados es fundamental para el entendimiento de los procesos de formación social y cultural en los países americanos. La exposición de la presencia histórica de estos individuos, la descripción de su trabajo, estilos de vida, su origen, los ritos fúnebres, junto al maltrato que sufrieron, son maneras de reivindicarlos, pues deben ser notados y reincorporados a la historia. Tal como mencionó Handler (1997, p.122), no era del interés de los dueños y capataces de haciendas y plantaciones elaborar un registro de estas personas, puesto que no los veían como tales, sino como parte del inventario de sus negocios, negándoles así la transcendencia de su identidad.

Por otro lado, la identidad es el elemento primordial de nuestro desenvolvimiento sociocultural, es lo que nos define como personas, sin embargo, una vez ocurrida la muerte, nuestra identidad se encuentra en riesgo, pues si no es documentada, estaremos perdidos en el tiempo, victimas del olvido y el abandono. La osteología proporciona las herramientas pertinentes para la recuperación de la identidad, lo que permite al mismo tiempo la reivindicación de la vida y la historia. Con este artículo se quiere promover la investigación osteológica en materia afrodescendiente, pues los esclavizados de origen africano han sido los individuos que más han sufrido el olvido y abandono, no sólo físico, sino también cultural. Ese olvido les ha negado el derecho a la identidad, dejándoles en cementerios que han sido destruidos, como el caso de Todasana, mientras que en otros casos los cementerios de esclavizados han sido exterminados. Herramientas como la osteología permiten honrar sus memorias y devolverles parte de sus identidades. 


\section{REFERENCIAS}

AGUILERA PORTALES, Rafael y GONZÁLEZ CRUZ, Joaquín. La muerte como límite antropológico. EI problema del sentido de la existencia humana. Gaceta de Antropología, 25(2), 1-10, 2009.

ALTEZ, Yara. Todasana: El trayecto de su singular identidad. Caracas: Consejo de Desarrollo Científico y Humanístico, 1999.

ALTEZ, Yara. El patrimonio del olvido y la investigación antropológica. Boletín Antropológico, 74, 265286. 2008.

ALTEZ, Yara, y RIVAS, Pedro. Arqueología e historia colonial de la parroquia Caruao. Caracas: Tropikos, 2002.

AUGÉ, Marc. Los no lugares: Espacios del anonimato, una antropología de la sobremodernidad. Barcelona, España: Gedisa, 1992.

BARRALES RODRÍGUEZ, Dehmian. Osteobiografía y aproximación facial forense del individuo inhumado en el Entierro 13 de Cañada de la Virgen, Guanajuato, México. Honolulu, Hawái: Atlantic International University, 2008.

BINFORD, Lewis. Mortuary practices: their study and their potential. Memoirs of the Society for American Archaeology, 25, 6-29. (1971).

BLAKEY, Michael y RANKIN-HILL, Lesley. The New York African burial ground: Unearthing the African presence in colonial New York. Washington, D.C.: Howard University Press, 2004.

BROTHWELL, Don. Desenterrando huesos: La excavación, tratamiento y estudio de restos del esqueleto humano. México: Fondo de Cultura Económica, 1987.

CARVAJAL, Ángel. Características métricas en maxilares inferiores masculinos contemporáneos: Una nueva propuesta para la asignación de la afinidad racial. Tesis de grado (Antropología), Universidad Central de Venezuela. Caracas, 2011.

CHAGUÁN, María Fernanda. Identificación con fines forenses de restos quemados. Un caso en estudio en el estado Aragua. Tesis de grado (Antropología), Universidad Central de Venezuela. Caracas, 2012.

CHICORA FOUNDATION INC. Grave matters - The preservation of African American cemeteries. South Carolina: Peoneers, Bellsouth volunteers, 1996.

FLOOD, Nancy. Cemetery demography. Toronto: University of Toronto, 1991.

GUERRA, Camila y REYES, Erika. Intervención antropológica en el cementerio parroquial de Penco. Actas del Tercer Congreso Latinoamericano de Antropología ALA 2012. Santiago de Chile, 2012.

HANDLER, Jerome. An African-type healerdiviner and his grave goods a burial from a plantation slave 
cemetery in Barbados, West Indies. En International Journal of Historical Archaeology, 1(2), p. 91-130. Plenum Publishing Corporation. 1997.

JAMIESON, Ross. Material culture and social death: African-American burial practices. Historical Archaeology, 29(4), p. 39-58, 1995.

KING, Charlotte. Separated by death and color: The African American Cemetery of New Philadelphia, Illinois. Historical Archaeology, 44(1), p. 125-137, 2010.

MANSILLA CASTAÑO, Ana. Patrimonio afroamericano en Brasil: Arqueología de los quilombos. Arqueoweb: Revista sobre Arqueología en Internet, 2(2), p. 2-15, 2000.

GÓMEZ MEJÍA, Juliana. Salud y cambio social: la bioarqueología y su potencial para interpretar el impacto biológico de la agricultura. Medellin: Boletín de Antropología Universidad de Antioquia, 26(43), 192-214. 2012.

MENDIZÁBAL, Amaia. Estudio antropológico y patológico de cementerios altomedievales en el País Vasco. Los casos del despoblado de Aistra y el castillo de Treviño. Munibe AntropologiaArkeologia, 62, 403-421, 2011.

MENDONÇA, Osvaldo, BORDACH, M. Asunción, \& ARRIETA, Mario. Arqueología y bioarqueología: interacciones y perspectivas para el registro fragmentado de una evidencia incompleta. Buenos Aires: Revista Argentina de Antropología Biológica, 14, 23-32, 2012.

MONROY, Albany. "En memoria de...". Aproximación arqueológica al Cementerio de los Extranjeros, La Guaria, Edo. Vargas. Tesis de grado (Antropología), Universidad Central de Venezuela. Caracas, 2016.

ORSER Jr., Charles. The archaeology of the African diaspora. En Annual Review of Anthropology, Annual Reviews, 27(1), 63-82, 1998.

ORSER Jr., Charles y FUNARI, Pedro Paulo. Archaeology and slave resistance and rebellion. En World Archaeology, Taylor \&amp; Francis, Ltd, 33 (1), p. 61-72, 2001.

OWSLEY, Douglas. Et al. Demography and pathology of an urban slave population from New Orleans. American Journal of Physical Anthropology, 74(2), p. 185-197, 1987.

PÉREZ, Antonio. Historia Local y Osteología de Rescate en el Antiguo Cementerio de Todasana. Tesis de grado (Antropología), Universidad Central de Venezuela. Caracas, 2019.

ROCA DE TOGORES, Consuelo. Análisis antropológico de los restos óseos del cementerio islámico de Bab Al-Hanax (Valencia). España: Universidad Miguel Hernández (Alicante), 1999.

RODRÍGUEZ, Yuleima. Cementerio General del Sur: Aproximación histórica y costumbres de los caraqueños vistas a través de la necrópolis. Mañongo, 36(19), p. 173-198, 2011.

SÁNCHEZ MARCOS, Iván. Aportación metodológica de campo en arqueología forense. Tesis de Maestría, Universidad de Granada, Granada, 2009.

TIESLER BLOS, Vera. Bases conceptuales para la evaluación de restos humanos en arqueología. 
México: UADY, 2006.

UROSA, María. Osteología de rescate: Introducción al estudio de restos óseos del parque histórico - arqueológico San Felipe, El Fuerte, Edo. Yaracuy. Tesis de grado (Antropología), Universidad Central de Venezuela. Caracas, 1998.

VELÁSQUEZ, Paula. Los cementerios... Territorios intersticiales. Hacia la Promoción de la Salud, 14(2), p. 24-38, 2009.

WRIGHT, Lori, GENOVEZ, José Vicente, VÁSQUEZ, Mario, BURGOS, Benito., GUERRERO, Inés, y SCHWARCZ, Henry. La osteología de rescate en Kaminaljuyú y algunas observaciones acerca de la dieta prehispánica en el Valle de Guatemala. XI Simposio de Investigaciones Arqueológicas en Guatemala 1997 (Guatemala: Museo Nacional de Arqueología y Etnología, pp. 558-567, 1998.

ZAKRZEWSKI, Sonia. Osteobiografía y la Población de la Plaza de España, Écija (Sevilla). Paleopatología y Bioarqueología: Contextualizando EI Registro Óseo. Actas del XIII Congreso Nacional de Paleopatología. Écija, Sevilla. 133-145, 2017

ZUCCHI, Alberta. Polvo eres y en polvo te convertirás: La muerte y su entorno en Venezuela hasta 1940. Caracas: Antropológica. 93(94), p. 3 -133, 2000. 